\title{
LA REVOLUCIÓN HIPOCRÁTICA DE PHILIPPE PINEL
}

\author{
José Luis Peset
}

I.H. - C.S.I.C.

\section{RESUMEN}

El profesor de patología Philippe Pinel es recordado en la historia de la medicina por haber revolucionado el tratamiento psiquiátrico a través de su Traité y de su práctica y su enseñanza clínicas. Mi intención es situar a Philippe Pinel en su tiempo, intentando comprender las líneas científicas, filosóficas y sociales que siguió. Se trata de una época en que se revaloriza el pensamiento clásico y antiguo, así el de los filósofos estoicos, reinterpretados por los pensadores de la Ilustración europea. También es un periodo en que la filosofía se asocia con la ciencia moderna, viviendo un momento de feliz hermanamiento.

PALABRAS CLAVE: Philippe Pinel, psiquiatría, Francia, siglos XVIII y XIX.

\section{SUMMARY}

The French Clinical Professor Philippe Pinel is remembered in History of Medicine as the great reformer of psychiatric treatment through his Traité and his clinical teaching and practice. My intention is to place Philippe Pinel in his time, trying to understand his scientific, philosophical and social lines. In this period the clasical and ancient thought is revalorized, so the stoic philosophers, reinterpreted by the European Enlightened thinkers. Also in this period, philosophy is asociated with modern science, living a happy brotherhood.

KEY WORDS: Philippe Pinel, psychiatry, France, $18^{\text {th }}$ and $19^{\text {th }}$ centuries.

En los últimos tiempos se insiste en el elogio que hace Platón, en su diálogo Fedón, de la calidad del método de los hipocráticos, que se basaría en la observación y en la experiencia y se confirmaría con los resultados. Se discute hoy si el objeto de interés de los médicos clásicos era el estudio de la entera naturaleza, de las leyes naturales, de la unión del alma con el cuerpo, o del cuerpo por entero. En cualquier caso, tanto Platón como Aristóteles encontraban en la medicina los modelos para la interpretación de la salud, del cuerpo y del alma, de la sociedad y de la naturaleza. Según Aristóteles los médicos terminan ocupándose de la naturaleza, los que se ocupan de la naturaleza concluyen interesándose por la medicina. Así Aristóteles y Descartes terminan 
reflexionando sobre la medicina, Galeno y Cabanis sobre la filosofía. Abundan los paralelismos entre estas disciplinas, que quieren explicar al hombre y a la sociedad, al cuerpo y al alma, al dios y a la naturaleza. Sin embargo, las diferencias son muchas en cuanto al método y a su uso. Se distingue el método a priori filosófico, pues para Platón el conocimiento es el recuerdo de los universales, del hipocrático, pues para los médicos vale la observación, la experiencia, las semejanzas y los resultados, lo que funciona. Se ha señalado por Mary Hesse la importancia que tiene en esta práctica la retórica de la persuasión, la evaluación contenida en las predicciones, la comprobación pragmática y el control instrumental del mundo exterior. Sin embargo, en la medicina hay que convencer, en la política hay que dominar.

También se insiste hoy en la importancia del pensamiento estoico en el mundo ilustrado. Se recuperan entonces muchas características del mundo anterior, aunque a través de las ideas generales de los estoicos de la antigüedad romana, reinterpretadas de nuevo en la época. Los valores ilustrados se apoyan en un doble principio: la identidad de la naturaleza humana, con variaciones de temperamentos y desigualdades de inteligencia y de resistencia física; y el progreso hacia un nuevo orden cosmopolita, con la diversidad de reglas, hábitos y costumbres de las sociedades humanas. Los valores sociales y morales no son solo racionales, pues el estoicismo exigía una percepción totalmente radical de la sociabilidad humana. Para Anthony Pagden esta concepción estoica del siglo XVIII tiene dos rasgos distintivos: el primero, es la insistencia en el autodominio; el segundo, la consideración del ser humano como parte integral de la naturaleza, desde el ámbito familiar y el compañerismo hasta la especie humana. Se pretende justicia para toda la humanidad, así como una visión integradora de cuerpo y alma. La Ilustración resucita el estoicismo para encontrar una ética laica que sustituyese a la cristiana. En vez de leyes independientes, el philosophe busca guía y sentido en sí mismo, siendo un ser afectivo y racional, ya no un anima con solo elección racional. La ley natural ya no puede tan solo basarse en preceptos, en principios racionales, sino también en sensaciones, sentimientos y pasiones.

Algunas ideas estoicas son fundamentales en la Ilustración, así el miedo a las pasiones, que deben ser dominadas. El sabio no carece de ellas, pero si cede, debe mantenerse a salvo y con pleno dominio. También la creencia en el orden natural, en un mundo perfecto que iguala a dios con las leyes naturales, a las almas incorporales con el dios motor del universo, que estaría así dotado de vida. Una naturaleza providencial mantendría la unidad del cosmos. Por tanto, hay posibilidad de reconciliación entre los impulsos naturales de preservación propia, la concepción o proyecto racional de la vida y el cosmos animado y 
completo. Se debe vivir de acuerdo con uno mismo, de acuerdo con la naturaleza, con aceptación del destino, como divino y natural, que puede llevar incluso a la renuncia a la vida. Se insiste, en fin, en la creencia en un tiempo circular, un eterno retorno, que vuelve al origen. El estoico es el modelo del philosophe francés, pues cree en la sabiduría y en la salvación de los pueblos. Se iguala virtud, sabiduría y naturaleza. La salud es acuerdo y obediencia con la naturaleza, por tanto con la sabiduría y con dios.

En este sentido, Jackie Pigeaud profundiza en el análisis de Cicerón hecho por Philippe Pinel, quien recomienda para enderezar el alma la lectura de las Tusculanae disputationes, así como otros muchos autores clásicos, Plutarco, Epicteto, Platón, Séneca, Tácito... El médico francés recoge sin embargo la antigua separación entre filosofía y medicina, el miedo de los médicos a llegar a los elementos geométricos, Galeno contra Platón. Con Cicerón se restaura así esa dualidad - el hombre doble cartesiano- y por tanto el necesario combate de la vida anímica. Esta se muestra así como sucesión, tiempo, causa, como combate interior, con duelo, victoria o derrota... también como moral, incluso como cambio social, la República romana se compara con la Revolución francesa. El enfermo mental es capaz de reacciones intelectuales y afectivas y por tanto es un ser moral cuya mente hay que vencer o convencer. Hay que balancear las pasiones, por no contrariar la naturaleza. Al restablecer el orden moral, Pinel es más aristotélico - y desde el modelo materialista médico, también más hipocrático - que estoico. La medicina recurre a la moral y a la política. La moral cura las enfermedades, evitando el vicio y el ocio, el mal tratamiento y la lesión que pueden llevar a la cronicidad y a la herencia morbosa.

Con Leibniz aparece la concepción de un tiempo que anima a la materia, que puede cambiar, progresar o sucumbir. Pero Pinel está tomando su idea de tiempo, su idea de orden del enfermo que observa, de la sociedad que hereda, de la ciencia que muestra sus leyes, de la naturaleza que posee la perfección divina. Mantiene un orden y un tiempo cíclicos y reparadores, temeroso del cambio, de la lesión y de la revolución. Como afirma Carlos Fuentes, ordenamos para que no nos invadan los sueños, para que el desorden nos perdone, o al menos evite, diría yo. La naturaleza nos ordena en el tiempo, la medicina - la psiquiatría y la higiene, en especial - así lo enseña. Es un tiempo hipocrático que para el mismo Leibniz en su Monadologie era equivalente a su armonía preestablecida. Pero como este mismo filósofo enseña y la ciencia empieza entonces a descubrir, el tiempo es también capaz de innovar y, por tanto, de crear o destruir. La Ilustración termina y el Romanticismo comienza.

Tanto por su educación eclesiástica como por la médica, Philippe Pinel es un gran lector de los clásicos. Recordemos que él es tonsurado, como Esqui- 
rol, aprendiendo en escuelas religiosas pedagogía y leyendo a los clásicos, saberes útiles para el uso del tratamiento moral. Hijo de un profesional de la medicina, fue un buen estudiante en Montpellier, donde su interés por los problemas de la vida se enriqueció con el vitalismo. Llega a París coincidiendo con la muerte de Rousseau, cuyos escritos conoció bien. Cultiva las matemáticas y la historia natural, siguiendo la propuesta geométrica de Barthez o la disección anatómica de Buffon. Pero su interés es el ser humano, su comportamiento, corporal o mental, en salud y enfermedad. En los estudios profesionales y en la biografía científica de Pinel se empieza por la ciencia y se termina por la medicina. Según Cuvier, fue un geómetra que se convirtió en médico. Al dedicarse a la medicina, seguirá los consejos sobre leer y practicar de Giorgio Baglivi, a quien edita en 1788. Unirá la preocupación científica con la clínica gracias a este autor, su método había reunido observación y experimento, aforismos curativos y axiomas generales. Llegará, por tanto, desde el estudio del movimiento animal, al del comportamiento de la mente humana. Tuvo una actividad intensa, científica, docente y clínica, en editoriales y revistas, en instituciones públicas y privadas... pero calma y discreta, hasta que los acontecimientos de la Revolución lo llevarán a primera fila en los grandes hospitales y en l'École de santé de París. La figura altruista, sabia y atractiva del philosophe será sustituida por el poderoso, erudito y ordenado professeur. Vivió, sin duda, un cambio social importante, que se apunta al fin de la monarquía absoluta, y que la Revolución acelera. Es el cambio de la sangre por el mérito, pero también la aparición del buen rey y del buen padre, del código Napoleón y de la nación francesa. Al buen filósofo suceden los sabios y poderosos clínicos y científicos franceses.

La aparición de la figura del bon Pinel, en que insiste Dora Weiner, es paralela a la del buen Hipócrates. En el Museo Fabre de Montpellier se encuentra un cuadro de 1792 de A.-L. Girodet, discípulo de David, en que se representa a Hipócrates negando su auxilio a los persas, enemigos de su patria. Es frecuente en la época este tipo de pintura, que toma ejemplos morales y políticos de la historia antigua. Es considerado Hipócrates como el sabio estoico que no quiere dinero, ni tiene necesidades ni deseos, tan solo sirve a su patria Atenas y no a sus enemigos los persas. Otros cuadros representan a Hipócrates en conversación con Demócrito, en la que confirmaría las teorías del equilibrio de contrarios, que iniciaría Alcmeón de Crotona. Otros a Arquímedes en Siracusa, constructor de máquinas de guerra, muriendo ante las tropas romanas, distraído con sus cálculos. El sabio se interesa por su saber, pero también por su uso adecuado. En este sentido, Cabanis recuerda la defensa que Hipócrates hace de los europeos, frente a los asiáticos, de la vida y leyes de su pueblo frente al enemigo, de la democracia frente al despotismo. 
En la facultad de medicina de Montpellier - $\mathrm{y}$ en todas las instituciones médicas de la época - está siempre presente Hipócrates, en el busto que allí se inaugura, en el juramento, en la enseñanza de la clínica. La divisa y el sello de la escuela y el libro que se entrega en doctorado mostrarán a lo largo de su historia la presencia del hipocratismo. Hay en la época muchas ediciones de Hipócrates, pues la cultura francesa se apoya en un profundo interés por el mundo clásico, que se ve en las facultades, en las órdenes e instituciones enseñantes, en las academias, así como en el Colegio de Francia. El arte y la literatura se vuelven hacia el neoclasicismo, a su vez la medicina retoma las ideas hipocráticas. La Société Royale de Médécine desde 1776, y los redactores de las topografías médicas, inician el estudio de las enfermedades en el medio humano y geográfico en que se desarrollan. Con orientación hipocrática, el estudio del medio comprende el clima, la geografía y la vida humana. Es el estudio del hombre en la naturaleza, así como de la propia vida que se considera bella, justa y perfectible. Es una defensa de lo propio contra lo ajeno y, con frecuencia, contra lo nuevo.

El gran respeto por la tradición que hereda, está siempre presente en las obras de Pinel. De Hipócrates retoma tanto la libertad ante las interpretaciones teóricas, como el entusiasmo por la observación y la descripción de enfermedades. Sus elogios hacia Hipócrates son entusiastas. En su Olimpo de filósofos - Bacon y Descartes, Locke y Condillac, Linneo, D'Alembert y Buffon- es introducido Hipócrates de forma curiosa. Lamenta que Bacon no se haya ocupado de la medicina, por su falta de conocimientos en la observación de enfermedades, pero acepta su palabra de que todo se encuentra ya en Hipócrates. Debe apoyarse en su más conocido texto en The Advancement of Learning de 1605, ya que en otros textos acusa Bacon a Hipócrates de exceso de empirismo y a Galeno de exceso de teoría. Según Ann F. La Berge, para Pinel sería Hipócrates un empirista, pero para Cabanis sería el médico-filósofo, con un método propio de observación. En el siglo XVIII, sobre todo entre los médi$\cos$, se acepta que Hipócrates asegura la verdad por su antigüedad, por su valor como clásico, pero incluso por la certeza que su método permite. Así este retorno a Hipócrates a través de Bacon justifica la unión de ciencia y medicina, que prescribe Pinel en su Nosographie philosophique. Junto a la enseñanza del libro Epidemias es preciso añadir la ciencia moderna, que refuerza el método descriptivo en las ciencias físicas, en el mecanicismo y el vitalismo, en el estudio de la organización del ser vivo. Puede servir el griego tanto para la más cuidadosa observación clínica, como para aceptar el apoyo de los movimientos científicos. Así, Philipppe Pinel en sus estudios sobre la mente humana puede aparecer como el heredero de los grandes clínicos, Sydeham, Baglivi o 
Cullen, y como científico entusiasta de las modernas interpretaciones de las pasiones hechas por Chrichton poco antes de la aparición de su Traité.

Pero centrémonos en la época y en la nación en que Pinel escribe, en la tradición francesa y en los cambios que la Revolución introdujo. En sus historias clínicas, las imágenes que pueblan los episodios revolucionarios - reyes y clérigos, militares y ricos, sabios y artistas - enriquecen la nueva historia natural de la enfermedad mental. Para él los años de bruscos movimientos en que pudo estudiar la manía, los años en que se hizo cargo de Bicêtre y de la Salpêtrière, fueron momentos decisivos, pues la enfermedad cambiaba, se liberaba y se expresaba. Es época revolucionaria, de grandes pasiones, que pueden producir la manía en todas su formas.

Como definió la actriz María Casares, el principal argumento de la cultura francesa es el control de las pasiones. En la obra del gran pensador del Barroco, René Descartes, las pasiones son reacciones, y por medio de ellas se produce el contacto entre el yo dotado de pensamiento y el cuerpo dotado de extensión. Como señala Jean-Maire Beyssade, en Les passions de l'âme esta unión es combate, por contraste y comparación. La fuerza con que el alma mueve el cuerpo es irreductible a las leyes físicas del cuerpo; la fuerza con que el cuerpo causa en el alma sentimientos y pasiones e inclina nuestra voluntad, es irreductible a la voluntad del alma. Las pasiones preparan e incitan al alma a querer las cosas para las que las pasiones preparan al cuerpo. La pasión dispone al alma a querer las cosas que la naturaleza dicta como útiles. Por tanto, se rompe la distinción, esencial en metafísica, entre alma y cuerpo, pues la unión de cuerpo y mente permite transmitir sensaciones, apetitos y emociones.

Para Descartes - siguiendo su orden metódico - las pasiones simples y primitivas, que quieren el bien y evitan el mal, serían la admiración que sigue el principio de lo nuevo; el amor y el odio, que siguen el principio del beneficio o del perjuicio; y siguiendo el principio o dimensión del tiempo, para el presente la alegría y la tristeza, para el futuro el deseo. El objeto de la pasión es considerado, según pueda beneficiarnos o perjudicarnos. Por lo tanto pierden éstas la consideración intrínsecamente negativa que para los estoicos y cristianos tenían, así como su intelección clásica como lucha entre almas. En el Traité de l'Homme se inicia la historia natural de las pasiones y se defiende su control para evitar sus peligrosos excesos.

Esta orientación será proseguida por Buffon en su Histoire naturelle de l'homme, de clara raigambre cartesiana, distinguiendo el hombre interno y el externo. En esta historia natural de las pasiones se señala su origen, como en Pinel, en el esfuerzo por sobrevivir y se teme el fuego que producen, la enfermedad que puede llevar a la gravedad y la cronicidad, así como a la heren- 
cia y la degeneración. El mecanicismo y el automatismo cartesiano, se enriquecen a través de Newton, buscando el estudio de los efectos generales y el hallazgo de las leyes naturales. La vida formada por moléculas con una atracción similar a la de Newton, que les permite organizarse, puede ser objeto de estudio de la lógica analítica, las matemáticas, la estadística, la química y la electricidad. El camino hacia la interpretación física del alma se exagerará en La Mettrie y en Helvétius, con apoyo en la organización, en especial del cerebro, que puede sin embargo ser susceptible de educación.

Maupertuis y Diderot representarán la hibridación de Newton con la modernidad de Leibniz. La materia se caracteriza por la sensibilidad, en sus más perfectos sujetos es capaz de pensar, actuar y sentir. La naturaleza es dinámica, está en continuo cambio. Las moléculas sensibles, la materia organizada, el calor, el movimiento.... dan sensibilidad, vida, incluso memoria, conciencia, pasiones y pensamiento. Así como también posteridad y metempsicosis, generación espontánea y transformismo. Se propone el estudio del todo, de la cadena de seres, de la materia viva, con espontaneidad de movimiento gracias a la organización. En el terreno que más nos interesa, la psicología pasa a ser historia natural, el estudio de los animales se convierte en guía del estudio de la vida humana.

A la influencia de los naturalistas hay que añadir la de Rousseau. Su creencia en la decadencia de la civilización culta y rica, se une a sus elogios de la vieja moral y de los héroes clásicos, que defendían religión y patria. Atenas corrompe a Esparta. Contrapone el buen salvaje de limpias pasiones, al perverso ciudadano cargado y castigado con vicios y enfermedades. La inocencia natural, el poder de la naturaleza, se contraponen al poder económico y político que lleva a la maldad social. La medicina y la ciencia, así como el dinero y la ambición corrompen. La ciudad se opone al campo, el ciudadano al campesino. Las buenas costumbres y pasiones del campo, se oponen a los vicios y enfermedades de la ciudad. La verdad está en el corazón humano, en el retorno a la naturaleza. La historia natural y la confesión van de la mano. En el libro IV de l'Emile Rousseau sitúa las pasiones en la pelea, no entre órganos o partes del alma, sino con la evolución temporal del propio cuerpo y con la adaptación del joven al cuerpo social. Las imágenes con que describe el nacimiento de la adolescencia - que toma del cosmos, de la política, de la ciencia, de la biología y de la patología - nos muestran las pasiones como un proceso a la vez temporal y relacional. Para controlarlas recomienda la ilustración, el maestro, el orden, la moral, la religión y la razón.

Tal como ha señalado Amélie Oksenberg Rorty, las pasiones surgen para este autor de la propia preservación, del «amour de soi». El bienestar es la expresión de las actividades basadas en la propia constitución, en la naturale- 
za, respaldada por dios. El adecuado placer — que para Platón era la armonía entre el cuerpo y el alma, o la representación de las condiciones necesarias para conseguir esta armonía - es para Rousseau la persecución de adecuados objetos, como pueden ser la amistad, la familia, la piedad o la ciudadanía, pero no de los falsos o inadecuados objetos, como la riqueza, la posición social, los bienes efímeros.

Rousseau busca una solución educativa - que se extiende como en Platón al nivel político - que evite conflictos entre una naturaleza presocial y sensitiva, que busca el bienestar propio, y las exigencias de su sociabilidad. Si la virtud del ciudadano - educado para la autonomía racional y la imparcialidad - consiste en aceptar la voluntad general, entra en conflicto con las necesidades del individuo y la familia. La educación de un pequeño microcosmos que es el individuo fracasa, con peligro para la armonía y la unidad de la mente. La separación de los deseos primitivos lleva a la separación de la naturaleza y la división de la mente. Rosseau reconocería una resignación razonable ante el consentimiento del ser humano a la voluntad general, la soberanía o la ciudadanía, por tanto ante una experiencia individual ambigua y conflictiva de esa mente dividida. Aparece así, señala Jean Starobinski, la imaginación en el estado de civilización que corrompe al buen salvaje. Ausente la imaginación en el estado de naturaleza, la educación y la política pueden conseguir que sus peligrosos efectos desaparezcan en la ciudad justa que Rousseau preconizaba. Freud recomendará un activo trabajo psicológico para aceptar esa renuncia razonable ante el principio de realidad.

Tissot convertirá estas ideas en higiene. Hay que conservar las costumbres de los aldeanos. La naturaleza se convierte en ordenadora de costumbres, del tiempo y de la medicina. El campo se prefiere a la ciudad, el día a la noche, la temperancia a los excesos y placeres. La regularidad y el equilibrio naturales - en el día y en la noche, en el trabajo y en el ocio, en el ejercicio y en el estudio, según la edad, estación y género - son las reglas esenciales de la medicina. Hay miedo de alejarse de la naturaleza, de separar el cuerpo de la naturaleza por los cambios en la sociedad. Hay miedo tanto al exceso de las pasiones, como al cambio social que irrumpe por aquellas décadas. Es la medicina clásica de las sex res non naturales. En el futuro la higiene insistirá en la dieta, en el género, en las edades del hombre, en el desarrollo del organismo, de órganos y temperamentos. Es una medicina de costumbres, retornos y regularidades. Sobre todo es un saber educador, como se señala en Platón y en Hipócrates. Galeno recomienda - según indica Luis García Ballester - la necesaria educación de las partes inferiores del alma.

Cabanis propondrá el conocimiento físico de la naturaleza humana, tanto médico como moral. De la sensibilidad física - irritación y motilidad- y de 
la organización - constitución según edad, sexo y temperamento- nace la psicología, una fisiología de la moral. Hay que estudiar las leyes de la organización - basadas en principios eternos - y las del movimiento. El sentir es el vivir, la vida es la solución de necesidades que a su vez producen el desarrollo y la organización de las facultades. Por lo tanto, la naturaleza humana es relacional y social. La enfermedad mental se estudia en las vísceras, en especial en el cerebro. Irá más allá de Pinel, del tratamiento moral y del dualismo. Creerá, por un lado, en las relaciones, que se establecen con las necesidades, los placeres, el trabajo o la sociedad. Creerá, por otro, en la anatomía patológica, perdiendo el miedo a contaminar el alma con materia y enfermedad. $\mathrm{Si}$ la sabiduría da la felicidad, como los estoicos y los ilustrados franceses creían, se ha de unificar medicina, ciencia y pedagogía, pues Cabanis defiende, como más tarde Condorcet, en la perfectibilidad del ser humano. Una primera pregunta, un primer conflicto se plantea aquí. Tal como Diderot se interrogó, ¿las moléculas activas y organizadas, pueden ser objeto de educación? ¿Puede la moral escapar de la ciencia?

Se encuentra Pinel ante unas teorías de las pasiones que son a la vez físicas y biológicas, progresivas y relacionales. Las pasiones aprovechan los cambios para actuar, la única defensa es por tanto el orden, en el control del cambio reside el papel del psiquiatra. Contra el desorden exterior, el médico busca el orden interior, en el hospicio y en el ser humano, en la naturaleza. Con el fin de establecer un orden permanente en la marcha y curso regular de los síntomas, ha sido perfeccionado el régimen físico y moral de los enfermos. Surge un orden espacial y social, corporal y anímico. Se ordenan los patios, en relación con la evolución de la enfermedad y su tratamiento, también el aseo, horarios, actividades y alimentación, pues según los clásicos las costumbres son una segunda naturaleza. La mente se recupera en el diálogo y en la distracción, en el ejercicio y en el trabajo, el ambiente médico da paso al familiar, social y natural. Se ordena por medio del trabajo, las costumbres y las conversaciones, de la relación con los enfermos, los médicos, los cuidadores y la familia, con la sociedad y con la naturaleza. Como en las instituciones privadas inglesas, aquí también el hospital debe ser un medio natural, en el que observar, ordenar y curar los enfermos.

El enfermo debe recuperar su orden natural, se consigue mejorando el medio - las reglas higiénicas de las sex res non naturales son esenciales - y las relaciones sociales - con el personal asistencial, con los otros enfermos, con la familia y el trabajo. La integración en la naturaleza será la regla de oro de los hospitales del siglo XIX. Los árboles, el aire fresco, la alimentación, la limpieza, la calefacción, la distracción, el ejercicio y el trabajo permiten al enfermo 
volver a su naturaleza física y, sobre todo, psíquica. La intención de Philippe Pinel era reducir a «principes fixes et puisés de la nature» la forma de dirigir los hospitales y sus enfermos.

Estudia en Bicêtre desde el primer año las variedades de la manía para deducir reglas fijas sobre los medios de dirigirlas. Como es bien sabido, Pinel se centrará en el análisis de la forma de presentación de esta enfermedad, en lo que no es sin embargo original. Se declara heredero de Areteo y Celio Aureliano - y podía citar a Sydenham y la nosografía more botanico - afirmando que quiere superarlos. Planea hacer la historia entera de los accesos de manía, sus causas, signos precursores, síntomas, formas variadas, los indicios que nos hacen confiar o temer, períodos sucesivos, duración, estación de su retorno, su terminación... La enfermedad sigue la marcha de la naturaleza, tal es la búsqueda del médico clínico, comparando los accesos de una locura intermitente con la vivacidad de los síntomas de una enfermedad aguda. En su clasificación, la manía recuerda a la clásica de las fiebres, pues las divide en continuas y periódicas, y éstas en regulares e irregulares. Éstas son las que mayor relación guardan con distintos cambios, por lo que estudia con detalle la aparición de los accesos: la edad del paciente, el tiempo que se distancian entre sí, su regularidad, la estación del año en que brotan, incluso la influencia solar, de la temperatura y las tormentas. Pinel, reinterpretando o reinventando a Hipócrates, plantea un método que toma de la historia natural. Aquí le influye Sydenham que sigue a Locke en el estudio de los fenómenos, los hechos se reúnen en un conjunto, formando un caso, o bien una especie. Si oscila entre los aforismos hipocráticos - que Giorgio Baglivi recomendaba - y las leyes naturales de la ciencia moderna, fue maestro en la descripción de enfermedades, herencia también hipocrática, a través de Sydenham y Boissier de Sauvages.

El médico moderno ha conseguido un método de observación en que se aúnan observación de hechos y coordinación lógica, empirismo, experiencia y comprobación práctica. Sigue el método cartesiano de buscar ideas claras y distintas, que lleven desde la simplicidad primitiva a sus grados de desarrollo, enlazando así con la lógica empirista y analítica de Locke y Condillac. Era preciso añadir un método analítico - lógico, matemático, anatómico o químico- para llegar a las enfermedades primitivas, que por complicaciones forman muchas otras y distribuirlas por afinidades de sus síntomas, causas o estructuras orgánicas de la parte afectada. Pero en psiquiatría la enfermedad es reacción y no lesión para Pinel. La locura es desorden de alguna de las facultades parciales de la mente humana, a veces el razonamiento, con más frecuencia la imaginación, de acuerdo con Rousseau. El desorden que se encuentra en las pasiones, en la sociedad y en las lesiones, es interpretado como 
alteración de las funciones de nuestra organización, que contraría las leyes de la naturaleza. Se produce el apartamiento de la marcha de la naturaleza, visible todavía en la salud y en la enfermedad aguda, la curación parece quedar reservada a enfermas jóvenes con corta duración.

$\mathrm{Su}$ esfuerzo por mostrar la manía como un esfuerzo de la naturaleza, semejante al de las fiebres, por conseguir la curación —aquí también la influencia de Hipócrates, de Sydenham y del vitalismo es notable - le hace considerar las que se originan en motivaciones externas las más fáciles de curar. Por tanto, denomina el capítulo XIII de la sección I: «Motifs qui portent à regarder la plupart des accès comme l'effet d'une reaction salutaire et favorable à la guérison». Busca en Sthal elevarse en la manía a la consideración general de un principio conservador, energía vital o vis medicatrix naturae, que intenta rechazar al igual que en las fiebres todo ataque perjudicial por una serie de esfuerzos felizmente combinados. Muchas han curado, pocas han resistido, sin duda por vicio orgánico o nervioso, que ha obstaculizado las leyes generales. En la manía no habrá lesión orgánica casi nunca, cuando la hay - cuando el tiempo pasado o el futuro introduce vicio orgánico - se cae en el camino sin retorno del desorden y la incurabilidad.

El exceso que pueden originar las pasiones lleva a la enfermedad. Con la exageración de las virtudes y de las tendencias generosas y magnánimas el hombre es conducido del libre ejercicio de la razón a la locura. Los obstáculos a los deseos y necesidades naturales - que igual que para Descartes, Buffon y Rousseau servirían para la preservación del individuo y la especie- son los causantes de las pasiones y éstas de la locura. La pasión es enfrentamiento entre obstáculo y deseo, con una sensación desagradable, o con la búsqueda de otra placentera. Se quiere la perpetuidad de la especie, con el triple objeto de conservar la existencia, la reproducción y la protección de nuestra raza en su tierna edad. Algunas de las necesidades son sin más las tradicionales que la higiene privada clásica preservaba en las sex res non naturales, aunque muchas de sus ideas sobre las pasiones están tomadas de Alexander Crichton, interpretándolas como simples fenómenos de la economía animal, sin ninguna idea de moralidad o inmoralidad. Son así analizadas en sus relaciones con los principios constitutivos de nuestro ser, sobre los que pueden ejercer efectos saludables o perjudicales, pues Pinel admiraba la obra de Crichton, en especial los rasgos científicos, como la introducción de la física y la anatomía patológica. Pero siguiendo su propia tradición, Pinel añade en su Traité las pasiones sociales, como honores, dignidades, riquezas, celebridad..., es decir, los excesos de la pujante burguesía, contrarios al término medio de su propia moral. Pero su principal aversión va contra el pasado, contra los enfermos que retoman en su 
peligrosa imaginación modelos del caduco régimen. Los afectados por la «manía devota» y por la «manía de creerse rey» son sujetos sin esperanza en la nueva sociedad emergente. Rousseau y Tissot están presentes, cuando Pinel advierte de los diversos excesos que las nuevas formas de vida introducen, sean la riqueza, el vicio, el estudio o la revolución. Burgués rico, sabio científico, viejo rey y antiguo beato, son los riesgos sociales que señala; en estos últimos también advierte la peligrosa incurabilidad, con sus acompañantes, la lesión anatómica y la herencia, que conducen a la degeneración.

Hay que recordar una vez más, cómo en el libro IV de l'Émile el ginebrino Rousseau - superando el análisis estático del racionalismo de Descartes o el empirismo de Locke - sitúa las pasiones en la lucha con la evolución temporal del propio cuerpo y con la adaptación del educando al cuerpo social, como un proceso temporal y relacional. Según Rorty también se toma de los estoicos estos conflictos de la infancia con la voluntad de la naturaleza, serían las experiencias sociales de Emilio y los traumas infantiles de Freud. En Pinel, como lector de Rousseau, aparece una rica psicogenia de la enfermedad mental, que abarcará tanto la educación, como la infancia, la vejez y la familia, que une a aspectos hereditarios y anatómicos. Es notable su interés por relacionar la enfermedad mental con la edad de los enfermos, tal como señala Dora Weiner. Los tipos de locura de Pinel tienen también ese mismo carácter relacional y temporal.

Aprenderá en Montesquieu y Rousseau que las pasiones despliegan gran potencia, puesto que de ellas se derivan tanto la moral como la política; por tanto, cuando no se pueden regular las pasiones, se llega tanto a alteraciones del orden psíquico como del moral, del natural como del social —así enseñan los estoicos-. Mantenerse dentro de los propios límites y del orden natural y social son los medios para controlar un saludable desarrollo. Tal como más tarde, entre los últimos consejos, dirá Jean-Jacques a su discípulo, es un error distinguir las pasiones entre permitidas y prohibidas. Todas son buenas mientras se dominan, malas cuando nos someten. La naturaleza prohibe al deseo, superar nuestras fuerzas; a la razón, querer más de lo que podemos obtener; a la conciencia, dejarnos vencer por la tentación. No depende de nosotros tener pasiones, pero sí el dominarlas. Las fuertes pasiones, que producen accesos periódicos, en enfermos de fuerte constitución y de mediana edad, producen manía curable, si se trata con sabiduría, trabajo y diversión. La característica esencial de esta forma de pensar en los ilustrados, muestra el camino hacia la libertad, hacia la liberación de la enfermedad, así como de las ataduras institucionales, pues los largos encierros llevan a la cronicidad de la manía.

Debemos pues señalar la adecuación que hay entre praxis política y praxis científica en la obra de Pinel, teniendo en cuenta que la psiquiatría se enfrenta 
desde sus orígenes tanto a alteraciones individuales como sociales. Así nace con peculiaridades respecto a otras clínicas, pues debe conservar una ordenación propia de la medicina mental y social, de la psiquiatría y la higiene, que se quiere continuadora y no peligrosa, reformadora y no revolucionaria, natural y no violenta. No sólo el estudio de las especies de enfermedades es tradición de Sydenham y Sauvages, también lo es el deseo de distribuir —es decir sujetar y definir - en el espacio y en el tiempo esas familias de enfermedades. Ese espacio es asilar, familiar, así como social e histórico, son terrenos que deben ser estudiados y ordenados. Lo que conseguirá en piedra Esquirol en Charenton, está en papel en Philippe Pinel, quien tras lamentar los problemas que tiene con la arquitectura de sus locales, de forma hipocrática estudia el medio de donde viene y a donde se conduce al enfermo, que si se aparta de la naturaleza enferma, si se aproxima sana.

El nuevo saber se oponía al Ancien régime, que consideraba los asilos como lugares de reclusión y castigo. Su dureza impedía la actividad del médico buscando curar la razón alterada, la razón oculta que debía ser liberada, devuelta a la sociedad y a la naturaleza.. Se debían estudiar los gustos y tendencias de los enfermos para dirigir los desviados en sentido contrario, engañar ideas obsesivas, aliar dulzura con firmeza, emplear medios represivos inocentes, pero jamás golpes o malos tratamientos que hacen incurable la locura. El hospicio, así como las formas de observación y curación se convierten en dura crítica contra el Ancien régime. Diversos símbolos se nos muestran aquí, sobre todo la identificación de la enfermedad mental como desorden, frente al orden de la salud, pero también frente al orden social. Toda la doctrina sobre el equilibrio de las pasiones - de origen clásico y barroco- es un alegato a favor de la moral y el orden burgueses. Orden y moral nuevos, que se levantan contra las tiranías del pasado, nobiliarias y despóticas, así como el tratamiento moral se levanta contra las brutalidades anteriores, incluidos los excesos de la revolución. Una segunda pregunta, un segundo conflicto. Tal como Montesquieu se preguntó, ¿las pasiones individuales y sociales, pueden ser objeto de educación? ¿Pueden las leyes escapar de la política?

Pinel se sitúa entre el philosophe de mediados del siglo XVIII y el savant de mediados del siglo XIX. Como ha señalado Didier Masseau, aquél era hábil en la adquisición y manejo de un saber, tenía conciencia de una misión que cumplir y voluntad de ejercer presión sobre la opinión pública para hacer triunfar ese ideal. Poseía una misión civilizadora, de emancipación, sin la que el hombre queda mutilado o alienado. Era consciente de ser un agente de la historia. Recurría al uso de la ciencia, pero sin especialización ni sistema; era un sacerdote laico, capaz de abnegación y renuncia. Maneja la ciencia, la pe- 
dagogía, la ética, así como la estética, conociendo la belleza y el sentimiento. Posee un círculo de convertidos, de iniciados, dispensa consejos a los grandes y a través de la prensa, de las cartas y libros, forma opinión. Por el contrario el sabio se encierra en su especialización, en sus instituciones y relaciones con el poder. Pero no pierde el dominio de la ciencia y sigue considerando esa misión civilizadora. Pinel pasará de las filas de los «filósofos», a intervenir moderadamente como los «ideólogos», a convertirse después en el «sabio» universitario. Serán necesarios muchos estudios, buenas relaciones y puestos institucionales. Será capaz de actuar sobre las mentes, de acuerdo con las tendencias que dominan el «fin du siécle». Sus conocimientos científicos y sus puestos institucionales en París le permiten separarse de hipnotizadores, mesmeristas, frenólogos y charlatanes. El tratamiento moral será la base del nacimiento de la moderna psiquiatría.

Iguala medicina y sacerdocio en la curación de la sociedad, en el mantenimiento del orden y del equilibrio. Se preocupa en su correspondencia familiar como Montesquieu - pero también como Rousseau, Condorcet y Cabanis - del progreso de la sociedad y de la ciencia y las artes. Si Apolo es para él el modelo de la armonía natural, también se interesa por los modelos históricos y sociales de romanos e ingleses, siguiendo a Montesquieu y a Gibbon. La filosofía moral debe llevar al bien público, sus figuras son el padre, la familia, la patria, los notables... médicos y sacerdotes. La medicina, por su papel técnico, es pedagógica y reformadora, nacional y universal. En la segunda edición del Traité - como señalan Jean Garrabé y otros autores - incrementará la importancia de la moral, de los filósofos y héroes clásicos, aumentando también el miedo a los desórdenes, a la lesión y a la herencia. El tiempo, el desequilibrio, los excesos llevan a la cronicidad y a la lesión orgánica, línea que Esquirol y sus discípulos desarrollarán. El enfermo incurable ya no tiene esperanza en el tiempo natural, queda preso entre amenazadoras paredes, dañado por la lesión orgánica y condenado a la herencia y a la degeneración. El miedo ilustrado a la decadencia - herencia clásica y cristiana - se ve aquí confirmado, si el médico fracasa como pedagogo y filósofo. Se trata de una línea que G. Lanteri-Laura señala para época posteriores. Lesión, herencia, desorden y locura, es un camino ya apuntado en Pinel y Esquirol. Esta línea coincide con la profundización del influjo de la ciencia moderna en la mente humana sana y enferma, cuyo funcionamiento quiere ser interpretado, como ocurre en otros dominios médicos y científicos desde el inicio del mundo moderno. 


\section{BIBLIOGRAFÍA}

BARTHEZ, P.J. (1801), Discours sur le génie d'Hippocrate, Montpellier, Tournel, an IX.

BeAuCHAMP TOM, L. (1999), «Hume and the Nonhuman Animal», The Journal of Medicine and Philosophy, 24 (4), agosto, pp. 322-335.

Berge. A. F. La (2002), «The Rhetoric of Hippocrates at the Paris School», en David Cantor (ed.), Reinventing Hippocrates, Ashgate, Aldershot, pp. 178-199.

Beyssade, J.-M. (2001), Études sur Descartes, París, Seuil.

ALBERTAN COPPOLA, S. (1998), «La faculté de penser serait-elle une propriété de la matière», en S. Albertan Coppola, A. N. Chouillet (ed.), La Matière et l'Homme dans l'Encyclopédie, Langres, Klincksieck, pp. 31-40.

Cunningham, A. (2002), "The Transformation of Hippocrates in Seventeenth-century Britain», en D. Cantor (ed.), Reinventing Hippocrates, Ashgate, Aldershot, pp. 91-115.

Duchesneau, F. (1982), La physiologie des Lumières, The Hague, Martinus Nujhoff.

EHRARD, J. (1970), L'idée de nature en France à l'aube des Lumières, París, Flammarion.

Enciclopedia filosofica, Florencia, Sansoni, 1967, 2a. ed.

ESQUIROL, É., Sobre las pasiones, Joseph DAQUIN, La filosofía de la locura, Madrid, AEN, 2000, introducción de José Luis Peset.

FERrater Mora, J. (2002), Diccionario de filosofía, Barcelona, Círculo de Lectores.

Foucault, M. (1961), Folie et déraison: Histoire de la folie à l'âge classique, París, Plon.

GARCíA BALlESTER, L. (1997), «Introducción general», en Galeno, Sobre la localización de las enfermedades (traducción de S. Andrés Aparicio), Madrid, Gredos.

Garrabé, J. (dir.) (1998), Philippe Pinel, Le Plessis-Robinson, Synthélabo.

GAUCHET, M.; SWAIN, G. (1980), La pratique de l'esprit humaine, París, Gallimard.

GonZÁLEZ DE PABLO, A. (1998), «El tratamiento racional de la patología mental: hipocratismo y galenismo», en F. López Muñoz, C. Álamo González, Historia de la neuropsicofarmacología, Madrid, Eurobook-Universidad de Alcalá, pp. 23-37.

GREMK, MiRKo D. (1983), Les maladies à l'aube de la civilisation occidentale, París, Payot.

Hesse, M. (1980), Revolutions and Reconstrutions in the Philosophy of Science, Brighton, Harvester Press, 1980.

Huertas GarcíA-Alejo, R. (1991), «Prólogo», en J. E. D. Esquirol, Memorias sobre la locura y sus variedades, Madrid, Dorsa Ediciones, 1991.

IGLeSIAS, Mª C. (1984), El pensamiento de Montesquieu: política y ciencia natural, Madrid, Alianza.

Imbault-Huart, M. J. (1978), «Pinel, nosologiste et clinicien», Hist. Sci. Méd., 12(1), pp. 33-38. 
IMBAULT-HUART, M. J. (1987-88), «Concepts and realities of the beginning of clinical teaching in France in the late 18th and early 19th centuries», Clio Medica, 21(1-4), pp. 59-70.

Inauguration du buste d'Hippocrate faite à l'école de médecine de Montpellier, Montpellier, Tournel, an IX.

IZARN, P. (2000), «L'hippocratisme à Montpellier et dans la France méridionale de la fin du XVIIIe siècle au début du XIXe siècle», en R. Andréani, H. Michel, y E. Pélaquier (ed.), Hellénisme et Hippocratisme dans l'Europe mediterranéenne: autour de D. Coray, Montpellier, Université Paul Valéry, pp. 121-131.

JACOB, F. (1995), «Madness and politics: French nineteenth-century alienists' response to revolution», History of Psychiatry, 6 (4), diciembre, pp. 421-429.

JALÓN, M. (1993), La plaza de las ciencias, Valladolid, Junta de Castilla y León.

JimÉnez Girona, J. (1955), La medicina de Baglivi, Madrid, C.S.I.C., 1955.

KING, H. (2002), «The Power of Paternity: The Father of Medicine Meets the Prince of Physicians», en David Cantor (ed.), Reinventing Hippocrates, Ashgate, Aldershot, pp. 21-36.

Koutouvidis, N.; Marketos, S. G. (1995), «The contribution of Thomas Sydenham (1624-1689) to the evolution of psychiatry», History of Psychiatry, 6 (4), diciembre, pp. 513-520.

LAVABRE-BERTRAND, T. (2000), «Place de l'hippocratisme dans le vitalisme montpelliérain», en R. Andréani, H. Michel, y E. Pélaquier (ed.), Hellénisme et Hippocratisme dans l'Europe mediterranéenne: autour de D. Coray, Montpellier, Université Paul Valéry, pp. 133-148.

Laín EnTRAlgo, P. (1961), La historia clínica. Historia y teoría del relato patográfico, Barcelona, Salvat.

Laín Entralgo, P. (1970), La medicina hipocrática, Madrid, Revista de Occidente.

Laín EnTralgo, P.; Albarracín Teulón, A. (1961), Sydenham, Madrid, CSIC.

LEPENIES, W. (1998), Ascesa e declino degli intellettuali in Europa, Bari, Laterza.

LLOYD, G. E. R. (2000), «Filosofía y medicina en la antigua Grecia: modelos de conocimiento y sus repercusiones», Asclepio, 52 (1), pp. 111-125.

MARSET, P. (1971), «El punto de partida de la obra psiquiátrica de Pinel», Medicina española, 65, pp. 390-404.

MARSET, P. (1972), «Veinte publicaciones psiquiátricas de Pinel olvidadas», Episteme, 6 (3-4), pp. 163-195.

MARSET, P. (1978), «La Psiquiatría durante la Revolución francesa: la obra de Pinel», Estudios de Historia Social, 7, pp. 217-287.

MARTíNEZ PÉREZ, J. (1998), «Nuevas respuestas a una conducta desviada: sobre los fármacos en el tratamiento de la locura durante el siglo XIX», en F. López Muñoz, C. Álamo González, Historia de la neuropsicofarmacología, Madrid, Eurobook, Universidad de Alcalá, pp. 51- 78. 
MASSEAU, D. (1994), L' invention de l'intellectual dan l'Europe du XVIIIe siècle, París, PUF.

MAUREL, M.-Ch. (1998), «Le passage de la matière inerte á la matière vivante et les débuts de l'approche scientifique», en S. Albertan Coppola, A. N. Chouillet (ed.), La Matière et l'Homme dans l'Encyclopédie, Langres, Klincksieck, pp. 71-79.

MonTI, M. T. (1997), «Les dynamismes du corps et les forces du vivant dans la physiologie de Haller», en G. Cimino, F. Duchesneau, Vitalisms from Haller to the Cell Theory. Proceedings of the Zaragoza Symposium. XIXth International Congress of History of Science, 22-29 August 1993, Florencia, Leo S. Olschki, pp. 41-66.

MonTIEL, L. (1998), «La medicina de la mente en el periodo moderno», en F. López Muñoz, C. Álamo González, Historia de la neuropsicofarmacología, Madrid, Eurobook, Universidad de Alcalá, pp. 39-49.

NAKagAwA, H. (1998), «Spiritualité et matière chez Diderot l'encyclopédiste», en S. Albertan Coppola, A. N. Chouillet (ed.), La Matière et l'Homme dans l'Encyclopédie, Langres, Klincksieck, pp. 23-30.

Pagden, A. (2002), La Ilustración y sus enemigos, Barcelona, Península, ed. J. M. ${ }^{a}$ Hernández.

Pellicer, L. (2000), «A propos d'Hippocrate refusant les présents d'Artaxercès, esquisse de Girodet (Musée Fabre, Montpellier)», en R. Andréani, H. Michel, y E. Pélaquier (ed.), Hellénisme et Hippocratisme dans l'Europe mediterranéenne: autour de D. Coray, Montpellier, Université Paul Valéry, pp. 195-212.

PETER, J.-P. (1984), «Reparar el desorden del mundo: la medicina ilustrada ante la enfermedad epidémica (Bas-Poitou, 1784-1785)», en J. L. Peset (ed.), Enfermedad y castigo, Madrid, CSIC, pp. 3-26.

PeSET, J. L. (1993), Las heridas de la ciencia, Valladolid, Junta Castilla y León.

Pigeaud, J. (2001), Aux portes de la psychiatrie, París, Aubier.

Postel, J. (1981), Gènese de la psychiatrie: les premiers écrits de Philippe Pinel, París, Le Sycomore.

REY, A. (1936), «La medécine dans l'histoire des sciences», en IIIe Congrès International d'Histoire des Sciences, Lisboa, Académie Internationale d'Histoire des Sciences, pp. 273-275.

REY, R. (1997), «Lignes de force et tendances actuelles des études sur le vitalisme», en G. Cimino y F. Duchesneau, Vitalisms from Haller to the Cell Theory. Proceedings of the Zaragoza Symposium. XIXth International Congress of History of Science, 22-29 August 1993, Florencia, Leo S. Olschki, pp. 19-30.

Roger, J. (1989), Buffon, París, Fayard, 1989.

RoRTY, A. O. (1996), «The two faces of stoicism: Rousseau and Freud», Journal of the History of Philosophy, 34 (3), pp. 335-356.

Rusnock, A. (2002), «Hippocrates, Bacon, and Medical Meteorology at the Royal Society, 1700-1750», en D. Cantor (ed.), Reinventing Hippocrates, Ashgate, Aldershot, pp. 136-153. 
StARoBinski, J. (1971), Jean-Jacques Rousseau: la transparence et l'obstacle, París, Gallimard.

StARoBinski, J. (2002), El ojo vivo (trad. Julián Mateo), Ballorca Valladolid, Cuatro Ediciones.

SUEUR, L. (1995), «The survival of ancient medicine in modern French psychiatry», History of Psychiatry, 6 (4), diciembre, pp. 493-501.

TOELlner, R. (1997), «Principles and Forces of Life in Haller», en G. Cimino y F. Duchesneau, Vitalisms from Haller to the Cell Theory. Proceedings of the Zaragoza Symposium. XIXth International Congress of History of Science, 22-29 August 1993, Florencia, Leo S. Olschki, pp. 31-39.

Tuozzo, T. M. (1996), «The General Account of Pleasure in Plato's Philebus», Journal of the History of Philosophy, 34 (4), pp. 495-513.

WEINER, D. (1980) The clinical training of doctors: an essay of 1793, Baltimore, The John Hopkins University Press.

WeInER, D. (1999), Comprendre et soigner. Philippe Pinel (1745-1826). La médecine de l'esprit, París, Fayard.

Williams, E. A. (2002), «Hippocrates and the Montpellier Vitalists in the French Medical Enlightenment», en D. Cantor (ed.), Reinventing Hippocrates, Ashgate, Aldershot, pp. 157-177. 